\title{
Electroactive polyurea/CNT composite-based electrode for detection of vitamin $\mathrm{C}$
}

\author{
T. C. Huang ${ }^{1}$, L. C. Yeh ${ }^{2}$, G. H. Lai ${ }^{1}$, F. Y. Lai ${ }^{1}$, T. I. Yang ${ }^{3}$, Y. J. Huang ${ }^{4}$, A. Y. Lo ${ }^{1}$, J. M. Yeh ${ }^{2 *}$ \\ ${ }^{1}$ Department of Chemical and Materials Engineering, National Chin-Yi University of Technology, 41170 Taichung, \\ Taiwan, R. O. C. \\ ${ }^{2}$ Department of Chemistry, Chung Yuan Christian University, 32023 Chung Li, Taiwan, R. O. C. \\ ${ }^{3}$ Department of Chemical Engineering, Chung Yuan Christian University, 32023 Chung Li, Taiwan, R. O. C. \\ ${ }^{4}$ Cellular and Behavioral Neuroscience, Texas A\&M University, College Station, TX 77843, United States
}

Received 7 October 2015; accepted in revised form 27 December 2015

\begin{abstract}
The electrocatalytic oxidation of vitamin C at carbon paste electrode (CPE) modified with amino-functionalized multiwalled carbon nanotube/electroactive polyurea (AF-MWCNT/EPU) composite was investigated. We have synthesized novel electroactive polyurea composites containing MWCNTs functionalized with 4-aminobenzoyl groups by an oxidative coupling polymerization. Ultraviolet-Visible spectra and cyclic voltammetry studies confirmed the occurrence of efficient interaction between AF-MWCNT and EPU graft. Moreover, the electrocatalytic activity of vitamin C oxidation by utilizing aniline containing composites was evaluated, showing that the intrinsic electroactivity of AF-MWCNT/EPU-CPE had great potential application for detection of vitamin $\mathrm{C}$. The detection limit and sensitivity of this sensor was $1.2 \mu \mathrm{M}$ and $35.3 \mu \mathrm{A} \cdot \mathrm{mM}^{-1}$, respectively.
\end{abstract}

Keywords: polymer composites, electroactive polyurea, sensor, nanocomposites

\section{Introduction}

Since their discovery in the 1950s, conducting polymers have been extensively studied and showed great promise in a variety of applications [1-7]. Among various conducting polymers, polyaniline (PANI) has attracted much attention due to its ease of synthesis, unique and controllable chemical, electrical properties and long-term stability in air. However, the PANI synthesized by chemical and electrochemical methods shows low solubility in common solvents. In addition, few synthesized PANIs have defined structures and precise oxidation-reduction states [8], which make it difficult to understand the electron transport mechanisms in PANI. For these reasons, aniline oligomers can be considered as good model compounds for researching specific behaviours of PANI [9]. Faul et al. [10] synthesized (tetra) aniline-alkyl diblock compounds which self-assembled into single-crystalline two dimensional microplates and further studied their conductivity property. Moreover, electroactive polymers incorporated with aniline oligomers have attracted research attention because of their superior properties such as good solvent solubility, mechanical strength, and the biodegradable properties $[11,12]$. Other authors synthesized a series of electroactive polymers and studied their electrochromic behavior [13-15]. The multicolor of electroactive polymers could be controlled by changing $\mathrm{pH}$ values or the applied potential. Furthermore, a series of electroactive block copolymers with bioactive properties have also been synthesized $[16,17]$. The conductivity of electroactive polymer could stimulate cell growth, especially in neural or cardiovascular cells, which are sen-

\footnotetext{
${ }^{*}$ Corresponding author, e-mail: juiming@cycu.edu.tw

(C) BME-PT
} 
sitive to electrical signals. Hardy et al. [18] synthesized electroactive polystyrene (EPS) and doped it using various acids. Experimental results exhibited that the dielectric properties of EPS doped with large, organic acids resulted in increases of up to an order of magnitude in permittivity and energy storage density relative to pure polystyrene, while maintaining a relatively low dielectric loss, especially in the high frequency range. Yeh and coworkers prepared many electroactive polymers such as electroactive polyimide [19], electroactive epoxy [20], electroactive polyamide [21, 22], electroactive polyurea [23] and electroactive poly(azine-azo) [24] as anticorrosion coating materials and photoactive materials. Recently, many researchers utilized electroactive polymers serving as sensing materials. The unique properties including acid-base doping/ dedoping chemistry and redox behaviours make the electroactive polymers to be the potential candidates as chemical and fluorescent sensors [25-27]. Carbon nanotubes (CNTs) have attracted great attention in research since its discovery by Iijima [28] due to its unique physical and chemical properties, such as high mechanical strength, electrical, thermal stability and chemical stability [29]. CNTs are found mainly in two types: single walled carbon nanotubes and multi walled carbon nanotubes. Their characterization and properties have been comprehensively studied in the last two decades [30]. Recently, CNTs has been used as a filler to incorporate within the polymer matrix. The CNTs/polymer composites exhibit improved mechanical property, good barrier property and excellent electrical conductivity [2833]. Many reports in literature suggest that CNTs/ conducting polymer composites have great potential for use in vitamin $\mathrm{C}$ sensors $[34,35]$. Vitamin $\mathrm{C}$, an essential nutrient for human and certain animal species, is crucial for a range of metabolic reactions such as growth and tissue repair. It is also an antioxidant that prevents cell damage caused by free radicals [36].

In this study, vitamin $\mathrm{C}$ sensors were fabricated using hybrid materials that incorporated electroactive polyurea (EPU) covalently attached to amino-functionalized multiwalled carbon nanotubes (AFMWCNTs) to improve the sensitivity and detection limit of obtained sensors. The as-prepared AFMWCNTs are expected to provide reactive sites for obtaining co-oligomers by polymerization and hence improve the electrical conductivity of EPU. The ultraviolet-visible (UV-Vis) spectra revealed that the aniline oligomer segment on the EPU was able to interact with AF-MWCNTs. The results of the cyclic voltammetry $(\mathrm{CV})$ studies indicated that AFMWCNTs can enhance the current value of the AFMWCNT/EPU composites. Most importantly, the electrical conductivity of the AF-MWCNT/EPU composites reached a value of $4.31 \cdot 10^{-3} \mathrm{~S} / \mathrm{cm}$ at a MWCNT loading of $10 \mathrm{wt} \%$ in the composites, which was an increase of more than five orders of magnitude compared to the conductivity value of the neat EPU. The high conductivity and facilitation of the charge transfer processes between the AFMWCNT and EPU significantly enhanced the sensitivity and the detection limit of the AF-MWCNT/ EPU-CPE sensor for detecting vitamin C.

\section{Experimental}

\subsection{Materials and instrumentation}

N-Phenyl-p-phenylenediamine (NPPD, 98\%, Aldrich), hexamethylene diisocyanate (HDI, 98\%, Alfa), $p$-phenylenediamine (99\%, Aldrich), Polyphosphoric acid (PPA, 83\%, $\mathrm{P}_{2} \mathrm{O}_{5}$ assay), $\mathrm{P}_{2} \mathrm{O}_{5}(98 \%$, Aldrich), 4-aminobenzoic acid (4-ABAD, 99\%, Aldrich), ammonium persulfate (APS, 98\%, Merck), tetrahydrofuran (THF, 99 , Merck), N,N-Dimethylacetamide (DMAc, 99\%, Merck), N-methyl-2pyrrolidone (NMP, 99\%, Merck), L-ascorbic acid (vitamin $\mathrm{C}$, reagent grade, Aldrich), phosphate buffered saline (PBS, Aldrich), hydrochloric acid ( $\mathrm{HCl}, 37 \%$, Riedel-deHaën), pristine MWCNTs (99.5\%, P-MWCNTs, Golden Innovation Business Co., Ltd.), and acetone (99, Acros) were used as received without further purification. All the chemicals used were reagent grade, unless stated otherwise. X-ray photoelectron spectroscopy (XPS, Kratos Axis Ultra DLD) was used to characterize the extent of functionalization on the surface of the MWCNTs. Fourier Transform Infrared (FTIR) spectra were collected at room temperature (on a Jasco FTIR-4100 spectrometer) from samples prepared as pellets with $\mathrm{KBr}$. Mass spectrometry was carried out on a mass spectrometer (Bruker Daltonics IT, model: Esquire 2000, Leipzig, Germany) equipped with an electrospray ionization (ESI) source (Agilent, model: G1607-6001). The chemical structure of the oligoaniline was determined by ${ }^{1} \mathrm{H}$ nuclear magnetic resonance $\left({ }^{1} \mathrm{H}\right.$ NMR) spectroscopy (on a Bruker 400 spectrometer), using deuterated dimethyl sulfoxide $\left(\mathrm{d}_{6}-\mathrm{DMSO}\right)$ as the solvent. Samples were also 
characterized with UV-Vis absorption spectroscopy (using Jasco V-650 spectrometer). Electroactive properties of the resulting composites were obtained using VoltaLab 21 with three-electrode electrochemical cell in a double-wall jacketed cell. Structural characterization was carried out with transmission electron microscopy (TEM on a JEOL 200FX, acceleration voltage: $120 \mathrm{kV}$ ). Conductivity values of the AF-MWCNT/EPU composites were obtained with a four-point probe connected to a Keithley 2400 voltmeter constant-current source system.

\subsection{Functionalization of MWCNTs (AF-MWCNTs)}

The AF-MWCNTs were synthesized according to the procedure reported in literature [37, 38]. 4-ABAD (10.0 g), MWCNTs (5.0 g), PPA (300.0 g), and $\mathrm{P}_{2} \mathrm{O}_{5}$ $(75.0 \mathrm{~g})$ were mixed using a mechanical stirrer under nitrogen atmosphere. The mixture was heated to $100^{\circ} \mathrm{C}$ and allowed to react for $1 \mathrm{~h}$ at this temperature. Subsequently, the temperature was increased to $130^{\circ} \mathrm{C}$ and the mixture was maintained at this temperature for $72 \mathrm{~h}$ under nitrogen atmosphere. Then, water was used to precipitate the dark homogeneous mixture. The precipitates were washed with water and methanol in a Soxhlet extractor. Subsequently, the samples were freeze-dried for $48 \mathrm{~h}$ to obtain the final product $(7.84 \mathrm{~g})$ as a dark black powder (with a yield of $52.3 \%$ ).

\subsection{Synthesis of EPU and AF-MWCNT/ EPU composites}

\subsubsection{Synthesis of co-oligomer}

HDI $(0.84 \mathrm{~g}, 5 \mathrm{mmol})$ was dissolved in $10 \mathrm{~mL}$ of THF. The resulting solution was added into a solution containing $1.84 \mathrm{~g}(10 \mathrm{mmol})$ of NPPD dissolved in $10 \mathrm{~mL}$ of THF over a period of $30 \mathrm{~min}$. The resulting solution was stirred for $3 \mathrm{~h}$ and then the cooligomer was precipitated using $200 \mathrm{~mL}$ of distilled water. The precipitated co-oligomer was washed with distilled water and dichloromethane and dried under dynamic vacuum at room temperature $\left(25^{\circ} \mathrm{C}\right)$. The as-prepared co-oligomer was obtained in a yield of ca. $90 \% .{ }^{1} \mathrm{H}$ NMR $\left(\mathrm{d}_{6}\right.$-DMSO): $\delta=8.18(\mathrm{~s}, 2 \mathrm{H}$, due to $\left.\mathrm{H}_{5}\right), \delta=7.85\left(\mathrm{~s}, 2 \mathrm{H}\right.$, due to $\left.\mathrm{H}_{8}\right), \delta=7.27-7.23(\mathrm{~d}$, $4 \mathrm{H}$, due to $\left.\mathrm{H}_{6}\right), \delta=7.17-7.12\left(\mathrm{t}, 4 \mathrm{H}\right.$, due to $\left.\mathrm{H}_{10}\right), \delta=$ 6.98-6.90 (t, 8H, due to $\left.\mathrm{H}_{7}, \mathrm{H}_{9}\right), \delta=6.73-6.67(\mathrm{t}$, $2 \mathrm{H}$, due to $\left.\mathrm{H}_{11}\right), \delta=6.05-5.97\left(\mathrm{t}, 2 \mathrm{H}\right.$, due to $\left.\mathrm{H}_{4}\right), \delta=$ $3.12-2.98\left(\mathrm{~d}, 4 \mathrm{H}\right.$, due to $\left.\mathrm{H}_{3}\right), \delta=1.50-1.20(8 \mathrm{H}$, due to $\mathrm{H}_{1}, \mathrm{H}_{2}$ ).

\subsubsection{Synthesis of EPU}

EPU was prepared by simultaneously dissolving $0.536 \mathrm{~g}(1 \mathrm{mmol})$ of co-oligomer and $0.108 \mathrm{~g}$ $(1 \mathrm{mmol})$ of 1,4-phenylenediamine into $30 \mathrm{~mL}$ of a stirring solution that contained $25 \mathrm{~mL}$ of NMP, $2.5 \mathrm{~mL}$ of distilled water, and $2.5 \mathrm{~mL}$ of concentrated hydrochloric acid. Subsequently, a solution containing $0.457 \mathrm{~g}$ of APS and $2 \mathrm{~mL}$ of $1.0 \mathrm{M}$ aqueous $\mathrm{HCl}$ was added dropwise while stirring at room temperature. A black product was then precipitated by pouring the obtained solution into $300 \mathrm{~mL}$ of distilled water with continuous stirring for $12 \mathrm{~h}$. The mixture was filtered and washed with distilled water and acetone several times. The dedoped state of EPU was achieved by dispersing into a $1.0 \mathrm{M}$ aqueous ammonium hydroxide and stirred for $1 \mathrm{~h}$. The as-obtained product was then dried under dynamic vacuum at $40^{\circ} \mathrm{C}$ for $24 \mathrm{~h}$.

\subsubsection{Synthesis of AF-MWCNT/ EPU composites}

The AF-MWCNTs were dispersed in $10 \mathrm{~mL}$ of NMP and ultrasonicated for $1 \mathrm{~h}$. In addition, $1.07 \mathrm{~g}$ ( $2 \mathrm{mmol})$ of co-oligomer and $0.216 \mathrm{~g}(2 \mathrm{mmol})$ of $p$-phenylenediamine were dissolved in $25 \mathrm{~mL}$ of a solvent mixture containing $20 \mathrm{~mL}$ of NMP, $2.5 \mathrm{~mL}$ of distilled water, and $2.5 \mathrm{~mL}$ of concentrated $\mathrm{HCl}$. Subsequently, the dispersion and the solution were mixed. A solution containing $0.913 \mathrm{~g}$ of APS and $5 \mathrm{~mL}$ of $1.0 \mathrm{M}$ aqueous $\mathrm{HCl}$ was added dropwise into the above-prepared solution under stirring at room temperature. The resulting solution was allowed to react for $12 \mathrm{~h}$. Then, the reaction mixture was dispensed into $300 \mathrm{~mL}$ of distilled water to precipitate the product. The dedoped state of composites was achieved by dispersing into a $1.0 \mathrm{M}$ aqueous ammonium hydroxide and stirred for $1 \mathrm{~h}$. The product was washed several times with distilled water and dried under vacuum at $40^{\circ} \mathrm{C}$.

\subsection{Measurement of electrical conductivity}

The EPU and AF-MWCNT/EPU samples were doped by immersing in $1 \mathrm{M} \mathrm{HCl}$ at room temperature for $24 \mathrm{~h}$. The samples were collected by filtration, washed with distilled water, and freeze-dried for $48 \mathrm{~h}$. The samples for the conductivity measurement were obtained by applying a pressure of $3.0 \cdot 10^{3} \mathrm{psi}(20.96 \mathrm{mPa})$ to the EPU or AF-MWCNT/ EPU samples to form a $0.1 \mathrm{~cm}$ thick pellet with a diameter of $1.3 \mathrm{~cm}$. 


\subsection{Preparation of the CPE and modified CPE}

The unmodified CPE was prepared by thoroughly mixing $30 \mathrm{mg}$ of paraffin oil with $150 \mathrm{mg}$ of graphite in a mortar to form a homogeneous carbon paste. A portion of the carbon paste was filled firmly into one end of a Teflon tube (of about $3.0 \mathrm{~mm}$ in diameter) and a copper wire was inserted through the opposite end to establish an electrical contact. Sufficient packing was achieved by pressing the surface of the samples at the end of the Teflon tube against a bond paper until a smooth surface was obtained. The modified CPEs were mixed with the $30 \mathrm{mg}$ of paraffin oil, $150 \mathrm{mg}$ of graphite, and $7.5 \mathrm{mg}$ of each sample (EPU and AF-MWCNT/EPU) to form a homogeneous paste into the Teflon tube. The total mass of graphite and sample was set to $30 \mathrm{mg}$.

\subsection{CV studies of the EPU and AF-MWCNT/EPU CPE}

To study the redox behavior of EPU and AFMWCNT/EPU, two representative CPEs were examined systematically by $\mathrm{CV}$ in $100 \mathrm{~mL}$ of $1.0 \mathrm{M} \mathrm{H}_{2} \mathrm{SO}_{4}$ and the potential ranging from -0.2 to $1.0 \mathrm{~V}$.

\section{Results and discussion}

\subsection{Characterization of AF-MWCNTs}

AF-MWCNTs decorated with 4-aminobenzoyl moieties can act as reactive sites to graft aniline oligomers by oxidative coupling polymerization according to the reports in literature [37]. FTIR and XPS measurements were used to confirm the attachment of 4aminobenzoyl moieties on the surface of the PMWCNTs. As shown in Figure 1b, P-MWCNTs exhibited featureless FTIR spectrum. Nevertheless, there are clear differences of the spectrum between P-MWCNTs and AF-MWCNTs. The spectrum of AF-MWCNTs exhibits an clearly aromatic carbonyl $(\mathrm{C}=\mathrm{O})$ peak at $1640 \mathrm{~cm}^{-1}$, which was shifted from the carbonyl peak of carboxylic acid at $1666 \mathrm{~cm}^{-1}$ in 4-ABAD. This result may indicate the 4-aminobenzoyl moieties on the AF-MWCN structure.

XPS spectra of P-MWCNTs and AF-MWCNTs were shown in Figure 2. Surface elemental composition of pristine and AF-MWCNTs were analyzed by XPS, which is one of the best surface analytical techniques, providing useful information on the nature of the functional groups and also the defects on the surface of the sample. Figure 2a showed a significant increased intensity of the O1s peak and N1s peak in AF-MWCNTs as compared to the P-MWCNT sam-
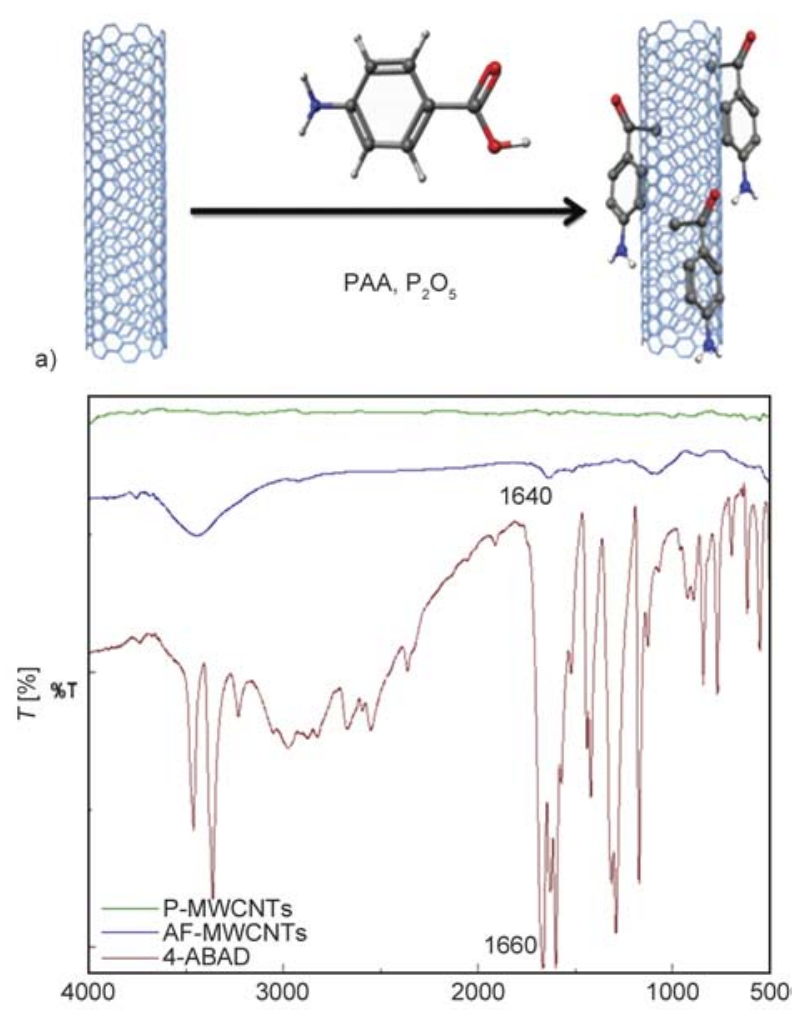

b) Wave number $\left[\mathrm{cm}^{-1}\right]$

Figure 1. (a) Functionalization of MWCNTs by using 4ABAD to obtain AF-MWCNTs. (b) Representative FTIR spectra of P-MWCNTs, AF-MWCNTs, and 4-ABAD.

ples. The increased intensity of these peaks could be attributed to the grafting reaction with 4-ABAD. The de-convoluted $\mathrm{C} 1 \mathrm{~s}$ peak of the MWCNTs showed a major C1s peak occurring at $284.4 \mathrm{eV}$ and a minor peak occurring at $285.2 \mathrm{eV}$ (Figure 2b). The former peak was assigned to the $\mathrm{sp}^{2}$ carbon atoms of the graphene sheets, and the latter peak was ascribed to the defects on the CNT walls [39]. As shown in Figure 2c, in the case of AF-MWCNTs, the XPS spectrum showed new peaks occurring at 285.6 and $287.2 \mathrm{eV}$ correspond to carbon in $\mathrm{C}-\mathrm{NH}_{2}$ and $>\mathrm{C}=\mathrm{O}$, respectively $[40,41]$. The presence of these peaks confirms the 4-aminobenzoyl moieties on the side walls of the AF-MWCNTs.

\subsection{Characterization of co-oligomer and EPU}

The synthesis routes for the preparation of cooligomer, EPU and AF-MWCNT/EPU composites were shown in Figure 3. The mass spectrum and 2D ${ }^{1} \mathrm{H}-{ }^{1} \mathrm{H}$ correlation spectroscopy (cosy) spectrum of the co-oligomer were shown in Figurr 4. In Figure 4a, the mass to charge ratio $(\mathrm{m} / \mathrm{e})$ for $\mathrm{C}_{32} \mathrm{H}_{36} \mathrm{~N}_{6} \mathrm{O}_{2}$ was 536.7. Found $535.7(\mathrm{M}-\mathrm{H})^{+}$. Figure $4 \mathrm{~b}$ showed the ${ }^{1} \mathrm{H}-{ }^{1} \mathrm{H}$ cosy spectrum confirming the structure of 

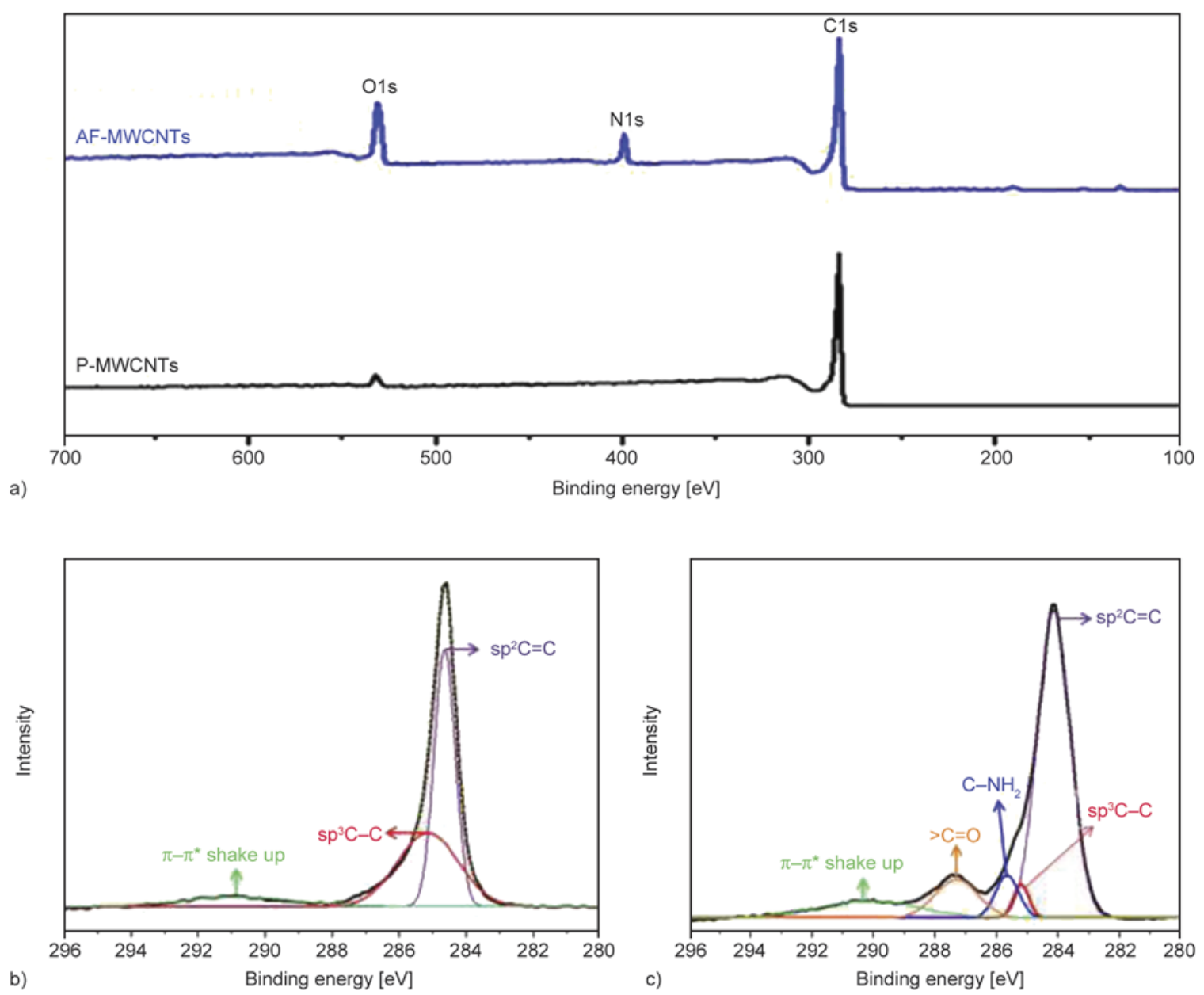

Figure 2. (a) Wide scan profiles of P-MWCNTs and AF-MWCNTs by XPS analysis. Curve fitting of C1s peaks originating from (b) P-MWCNTs and (c) AF-MWCNTs.

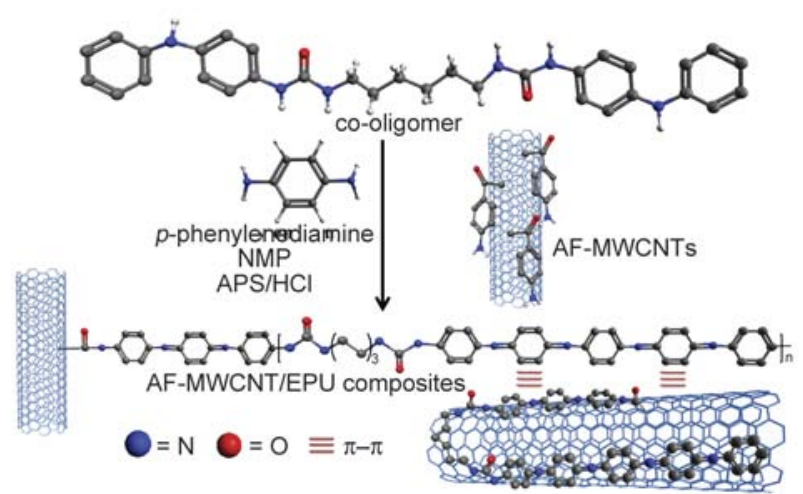

Figure 3. Synthesis route of the AF-MWCNT/EPU composites

the co-oligomer. The signals at 8.17, 7.38, and 6.03$5.99 \mathrm{ppm}$ can be assigned to the amino protons and the signals at 7.27-7.24, 7.17-7.12, 6.97-6.91, and $6.72-6.67 \mathrm{ppm}$ were attributed to the aromatic protons in the co-oligomer, and the signals at 3.07-3.05 and $1.42-1.30 \mathrm{ppm}$ were due to the alkyl protons.

\subsection{Characterization by UV-Vis spectroscopy}

The UV-Vis absorption spectra of EPU and AFMWCNT/EPU in NMP solution were utilized to examine the interaction between the electroactive polyurea and AF-MWCNT, as shown in Figure 5. The EPU showed two distinctive absorption bands at 300 and $593 \mathrm{~nm}$. The peak at $300 \mathrm{~nm}$ can be assigned to the $\pi-\pi^{*}$ transition of the benzenoid rings and the peak at $593 \mathrm{~nm}$ can be attributed to the $\pi-\pi^{*}$ transition of the quinoid rings along the backbone of the EPU chain. In contrast, the characteristic peak assigned to the $\pi-\pi^{*}$ transition band of the benzenoid rinds showed a blue shift from $300 \mathrm{~nm}$ for pure EPU to $296 \mathrm{~nm}$ for the AF-MWCNT/EPU composites. Moreover, the intensity of the peaks related to the $\pi-\pi^{*}$ transition of the quinoid rings was reduced in the AFMWCNT/EPU solution. This is because the quinoid units were stabilized by the strong $\pi$ - $\pi$ interaction between MWCNTs and EPU and the charge transfer from the polymer chain to MWCNTs [42, 43]. 

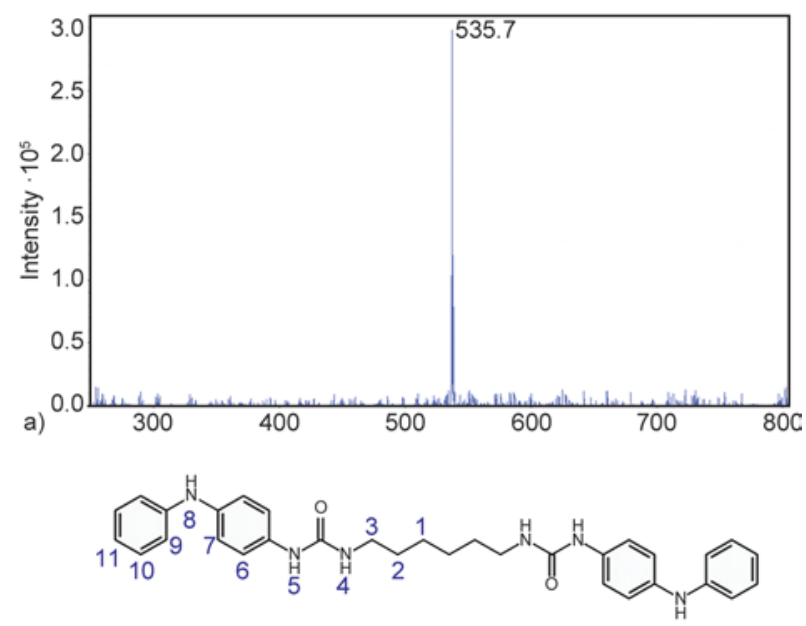

b)

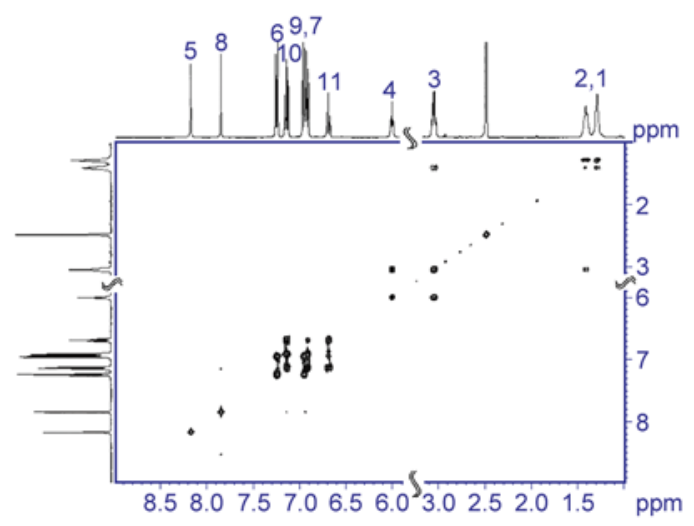

Figure 4. (a) Mass spectrum and (b) ${ }^{1} \mathrm{H}-{ }^{1} \mathrm{H}$ cosy spectrum of co-oligomer

\subsection{TEM characterization}

TEM images were used as a tool to confirm that EPU caused the change of the morphology on carbon nanotube surface and that the AF-MWCNT surface remained intact during the preparation of the AFMWCNT/EPU composites. For preparing the TEM sample, AF-MWCNT/EPU composites was dis-

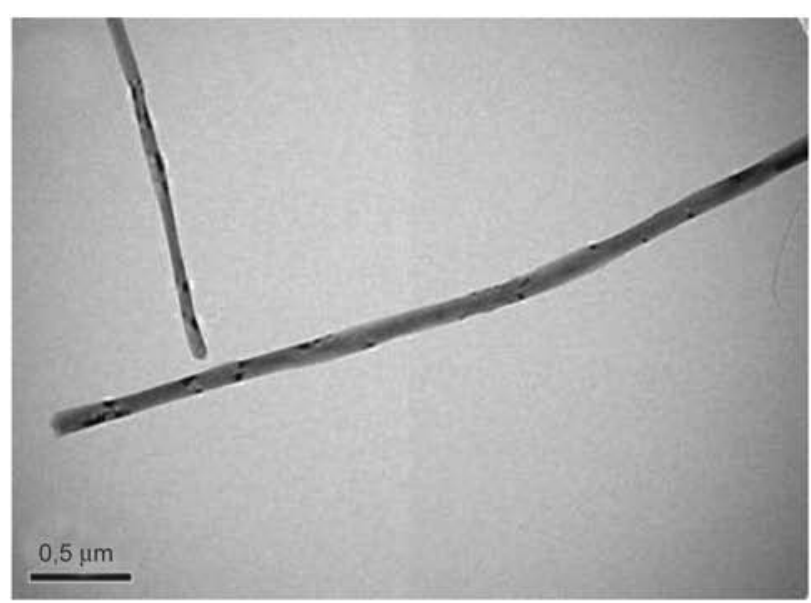

a)

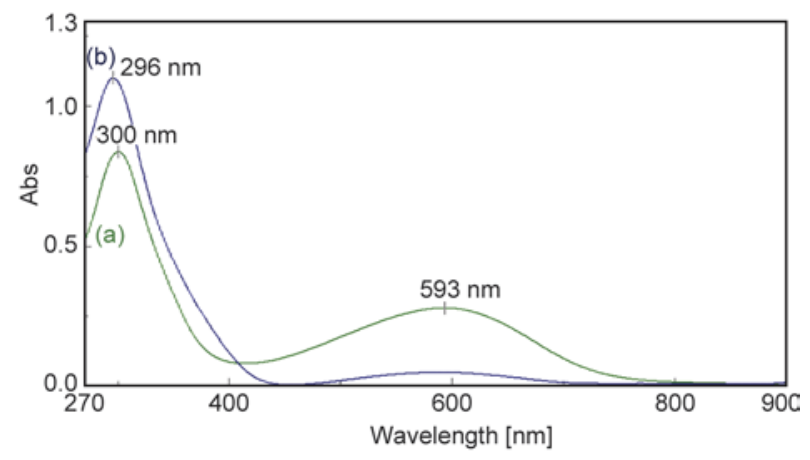

Figure 5. UV-Vis absorption spectra of (a) EPU and (b) AFMWCNT/EPU composites

persed and ultrasonicated in water for $1 \mathrm{~h}$. Subsequently, AF-MWCNT/EPU solution was then dropped on the copper grid and dried at room temperature. The surface of AF-MWCNTs is smooth, indicating that the surface of the MWCNT was intact after modification, as shown in Figure 6a. In contrast, the surface of AF-MWCNT/EPU was not smooth anymore, which can be attributed to the presence of the electroactive polymers on its surface, as shown in Figure 6b. These results confirmed that the AF-MWCNTs can be covered with EPU or other electroactive polymers by utilizing the oxidative coupling reaction [44].

\subsection{Conductivity measurement}

The conductivity of aniline-based electroactive polymers is lower than PANI, ranging between $10^{-7}$ to $10^{-4} \mathrm{~S} / \mathrm{cm}$ [38]. This is because that the aniline oligomers incorporated with nonconducting component to form electroactive polymers and there was little opportunity for the aniline oligomers to establish a channel for electron transport, leading to the low conductivities of the electroactive polymers. In

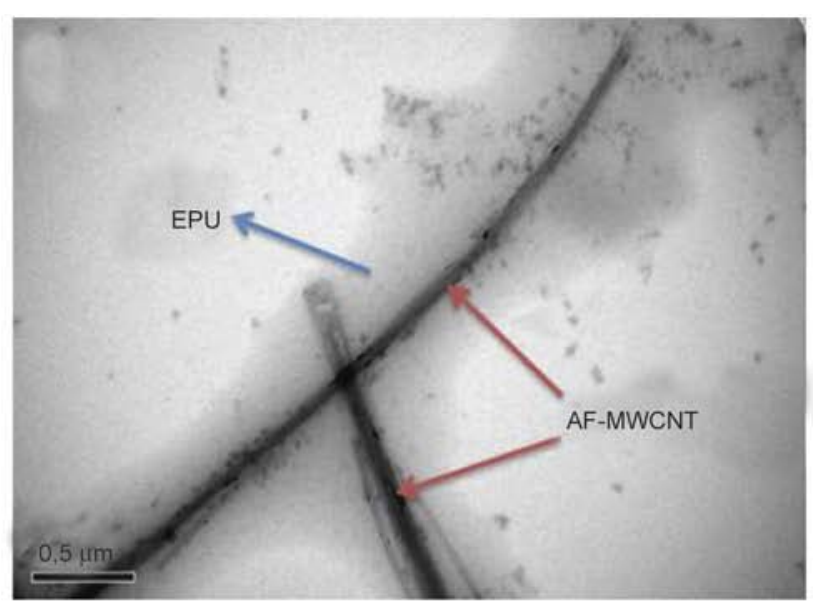

b)

Figure 6. TEM images of (a) AF-MWCNTs and (b) nanotubes present in the AF-MWCNT/EPU composites 
Table 1. The conductivity of AF-MWCNT/EPU

\begin{tabular}{|c|c|}
\hline $\begin{array}{c}\text { AF-MWCNTs Loading } \\
\text { [wt\%] }\end{array}$ & $\begin{array}{c}\text { Conductivity } \\
{[\mathbf{S} / \mathbf{c m}]}\end{array}$ \\
\hline 0 & $4.78 \cdot 10^{-8}$ \\
\hline 1 & $7.19 \cdot 10^{-7}$ \\
\hline 3 & $3.70 \cdot 10^{-6}$ \\
\hline 5 & $2.36 \cdot 10^{-5}$ \\
\hline 10 & $4.31 \cdot 10^{-3}$ \\
\hline 15 & $9.23 \cdot 10^{-3}$ \\
\hline
\end{tabular}

this study, we utilized AF-MWCNTs to improve the conductivity of the electroactive polymer. The electrical conductivity of AF/MWCNT/EPU composites increased five orders from $4.78 \cdot 10^{-8}$ to $4.31 \cdot 10^{-3} \mathrm{~S} / \mathrm{cm}$ with increasing the amount of AFMWCNTs from 0 to $10 \mathrm{wt} \%$ (Table 1). This result can be explained by the dopant effect, which involves an efficient charge transfer from the quinoid unit of EPU to AF-MWCNTs. CNTs are relatively good electron acceptors [45], while aniline oligomers in the EPU main chain could be considered as good electron donors. This donor-acceptor combination in the composites facilitates electron transfer, owing to the reduction of the energy barrier for electron transfer to occur from the valence band to the conduction band [46]. Therefore, the conductivity of the resulting AF-MWCNT/EPU composites could be significantly improved by introducing AF-MWCNTs into the EPU matrix.

\subsection{CV studies}

Figure 7 (a) showed the CV of the EPU and AFMWCNT/EPU composites. Both EPU and AFMWCNT/EPU composites showed three distinct pairs of redox peaks. The CV results could be attributed to the change of molecular structure of EPU.

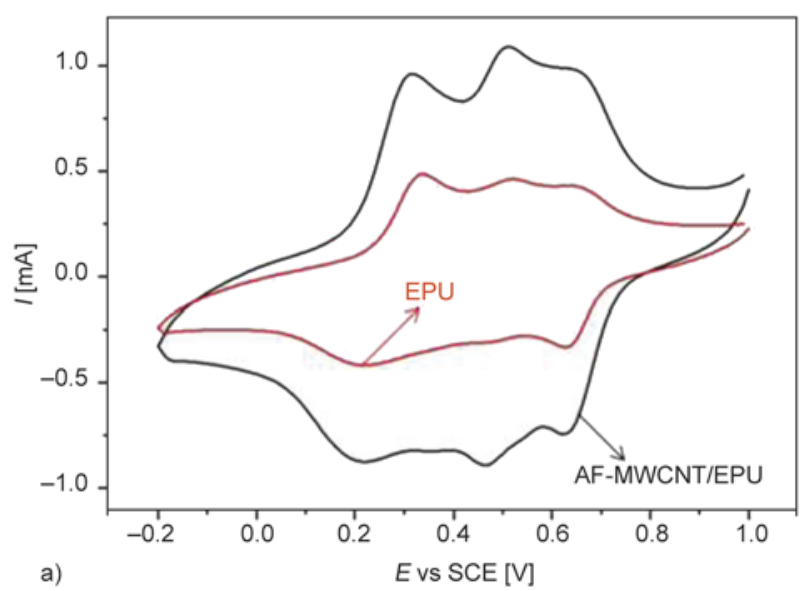

Three redox pairs originate from the transitions between Leucoemeraldine to Emeraldine I, Emeraldine I to Emeraldine II and Emeraldine II to Pernigraniline of the aniline oligomer in the main chain of EPU. Furthermore, with the MWCNTs acting as electrically conductive bridges inside the AF-MWCNT/ EPU composite, the diffusion length of the electrolyte ions was greatly reduced, resulting in an enhanced current compared to that of the neat electroactive polymers [45]. The CV responses for the AF-MWCNT/EPU-CPE were recorded at different scan rates ranging from 25 to $200 \mathrm{mV} / \mathrm{s}$, as shown in Figure $7 \mathrm{~b}$. As higher scan rates were applied, the oxidative peak potentials shifted to positive potential, and the reductive peak potentials shifted toward negative potential. Moreover, linear relationships between the peak currents and the square root of the scan rates with a square of regression coefficient $\left(R^{2}\right)$ of 0.99 for the sensor were observed, indicating that the electron transfer process of the electrode was a diffusion-controlled process [47].

\subsection{Electrochemical response of}

\section{AF-MWCNT/EPU-CPE toward vitamin C}

The prepared AF-MWCNT/EPU-CPE exhibited the current responses toward vitamin $\mathrm{C}$ as shown in Figure 8. Moreover, the oxidation current which occurred at $0.40 \mathrm{~V}$ versus $\mathrm{Ag} / \mathrm{AgCl}$ would continuously increase with increasing concentration of vitamin $\mathrm{C}$ from 0.0 to $8.0 \mathrm{mM}$. This result indicated that the aniline oligomer in AF-MWCNT/EPU-CPE has direct electrocatalytic properties to the oxidation of vitamin $\mathrm{C}$. The redox reaction process could be described by the following steps. Vitamin $C$ in the solution diffused toward the polymer modified elec-

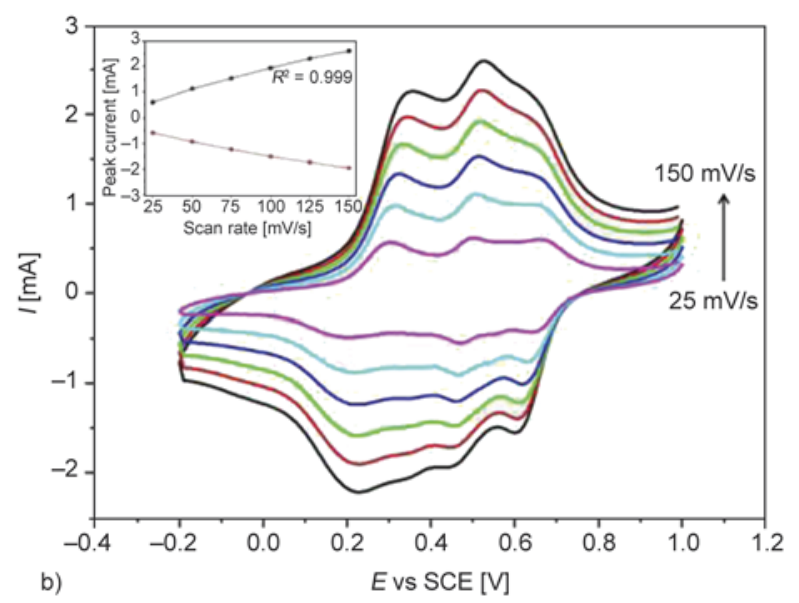

Figure 7. CV curves of (a) EPU and AF-MWCNT/EPU CPE and (b) AF-MWCNT/EPU-CPE in $1 \mathrm{M} \mathrm{H}_{2} \mathrm{SO}_{4}$ at different potential scan rates: $25,50,75,100,125$ and $150 \mathrm{mV} / \mathrm{s}$. Inset: plot of peak current versus square root of the scan rate. 


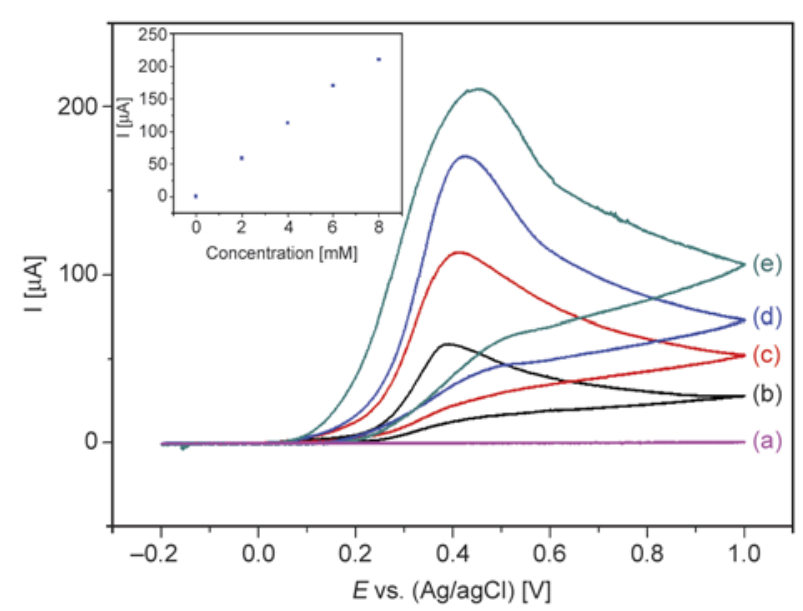

Figure 8. $\mathrm{CV}$ curves of AF-MWCNT/EPU-CPE with (a) $0.0 \mathrm{mM}$, (b) $2.0 \mathrm{mM}$, (c) $4.0 \mathrm{mM}$, (d) $6.0 \mathrm{mM}$ and (e) $8.0 \mathrm{mM}$ vitamin $\mathrm{C}$ concentrations

trode surface and reacted with the oxidized state of EPU, which led to the increase of the reduced state of EPU. This increase of the reduced state of EPU resulted in the increase of the oxidation currents $[48,49]$. The inset shows the peak currents plotted as a function of the amount of vitamin $\mathrm{C}$ added. A linear relationship with the vitamin $\mathrm{C}$ concentration in the range from 0.0 to $8.0 \mathrm{mM}\left(R^{2}=0.996, n=5\right)$ was observed.

At an applied potential of $0.40 \mathrm{~V}$, the successive addition of vitamin $\mathrm{C}$ from $10 \mu \mathrm{M}$ to $910 \mu \mathrm{M}$ in $0.1 \mathrm{M}$ PBS to the AF/MWCNT/EPU-CPE increased the current successively. This phenomenon occurred in $1.46 \mathrm{~s}$. The rapidity of the detection was attributed to the oxidation and reduction reactions occurring directly as shown in Figure 9. There was a linear relationship between the concentration of vitamin $\mathrm{C}$ added and the peak current obtained, as evidenced by the linear calibration curve of the amperometric response of the sensor to the concentration of vita-

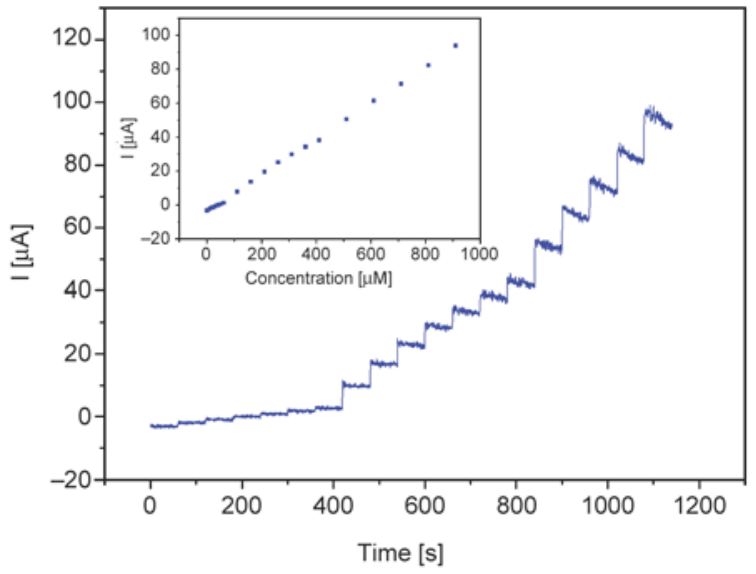

Figure 9. Amperometric current responses of AF-MWCNT/ EPU-CPE for successive addition of vitamin C into a $30 \mathrm{~mL}$ PBS solution stirred constantly. Inset shows the calibration curve between the current and the concentration of vitamin $\mathrm{C}$.

min $\mathrm{C}$ provided in the inset $\left(R^{2}=0.999\right.$ for AFMWCNT/EPU-CPE). The detection limit of the AFMWCNT/EPU-CPE vitamin C sensor was $1.2 \mu \mathrm{M}$ at $S / N$ (signal to noise ratio) of 3 and the sensitivity was $35.3 \mu \mathrm{A} \cdot \mathrm{mM}^{-1}$. The detection range, the sensitivity and the detection limit of the AF-MWCNT/EPUCPE comparable to those of most modified electrodes reported in literature (Table 2). The sensitivity and the detection limit observed in the present study were higher than that observed in most other reports in literature. There was also a great improvement in sensitivity and detection limit compared to previously reported studies [52]. To further study the stability of AF-MWCNT/EPU-CPE, the electrode was well preserved at PBS solution $\left(4^{\circ} \mathrm{C}\right)$ and detected at different times. In Figure 10, the current response did not significantly decay in the first week. After two weeks, the current response of the same electrode still reached $91.2 \%$ of the original

Table 2. A comparison of various types of ascorbate biosensors

\begin{tabular}{|c|c|c|c|c|c|c|c|}
\hline Modified electrode & $\begin{array}{c}\text { Detection } \\
\text { limit } \\
{[\mu \mathrm{M}]}\end{array}$ & $\begin{array}{l}\text { Sensitivity } \\
{\left[\mu \mathrm{A} \cdot \mathbf{m M}^{-1}\right]}\end{array}$ & $\begin{array}{c}\text { Applied } \\
\text { potential } \\
\text { (vs. } \mathrm{Ag} / \mathrm{AgCl}) \\
{[\mathrm{V}]}\end{array}$ & $\begin{array}{c}\text { Linear range } \\
{[[\mathrm{mM}]}\end{array}$ & $\begin{array}{c}\text { Optimum } \\
\text { pH }\end{array}$ & $R^{2}$ & Reference \\
\hline $\mathrm{EPI} / \mathrm{CPE}$ & 9.6 & ${ }^{\mathrm{a} N R}$ & 0.4 & ${ }^{\mathrm{a} N R}$ & 7 & 0.996 & [27] \\
\hline PANI/GCE & 0.4 & ${ }^{\mathrm{a}} \mathrm{NR}$ & $0.1-0.3$ & $0.0004-2$ & $6-7$ & 0.999 & [50] \\
\hline $\mathrm{PANI} /{ }^{\mathrm{b}} \mathrm{OAA} / \mathrm{PT}$ & 500 & ${ }^{\mathrm{a}} \mathrm{NR}$ & 0.34 & $5-60$ & 7 & ${ }^{\mathrm{a}} \mathrm{NR}$ & [51] \\
\hline EPU/CPE & 6.1 & 15.4 & 0.42 & $0.05-0.5$ & 7 & 0.996 & [52] \\
\hline PANI/ITO & 18.0 & 12.0 & -0.135 & $0.05-0.4$ & 7 & 0.999 & [53] \\
\hline MWNT-g-poly(2,5-dimethoxyaniline)/ITO & 0.1 & 12.78 & 0.32 & $1.0-5.0$ & 7 & 0.999 & [54] \\
\hline c pAPTT/GCE & 1.4 & 10.0 & 0.3 & $0.01-0.2$ & 4 & 0.998 & [55] \\
\hline AF-MWCNT/EPU/CPE & 1.2 & 35.3 & 0.4 & $0.01-0.91$ & 7 & 0.999 & This work \\
\hline
\end{tabular}

${ }^{\mathrm{a}} \mathrm{NR}=$ Not reported

${ }^{\mathrm{b}} \mathrm{OAA}=$ orthanilic acid

${ }^{c}$ pAPTT $=$ poly-3'-(2-aminopyrimidyl)-2,2':5',2'-terthiophene 


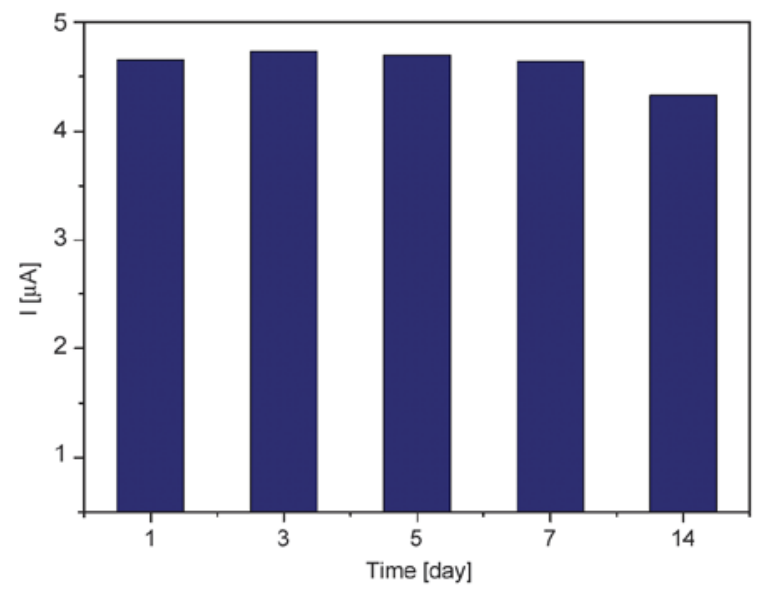

Figure 10. The relationship between the respond current of $100 \mu \mathrm{M}$ vitamin $\mathrm{C}$ and time

current. These results revealed the developed AFMWCNT/EPU-CPE is an electrode with excellent reliability for sensing vitamin $\mathrm{C}$.

\section{Conclusions}

The electroactive polyurea incorporated with AFMWCNTs was prepared to modify the CPE and the resulting AF-MWCNT/EPU-CPE was utilized to detect vitamin C. UV-Vis and CV tests confirmed that the AF-MWCNT/EPU composite was successfully synthesized and hence led to effective site-selective interactions between the quinoid ring of EPU and AFMWCNTs, facilitating charge-transfer processes between the two components. Furthermore, the conductivityy of EPU was improved by five orders when incorporating AF-MWCNTs. Therefore, the electrocatalytic property of AF-MWCNT/EPU composites toward the oxidation of vitamin $\mathrm{C}$ was significantly enhanced. The detection limit and sensitivity of AF-MWCNT/EPU-CPE for detecting vitamin C was $1.2 \mu \mathrm{M}$ at $S / N$ of 3 and $35.3 \mu \mathrm{A} \cdot \mathrm{mM}^{-1}$, respectively. The prepared AF-MWCNT/EPU carbon paste modified electrode showed excellent sensitivity and detection limit for determination of vitamin C. We are confident that the results of this study will significantly contribute to the advance of polymer composite sensors.

\section{Acknowledgements}

This research was supported by the Ministry of Science and Technology, R. O. C. (MOST-103-2221-E-167-037-MY3 and 104-2811-E-167-001). We thank Mr Chun-An Chen for the schematic design.

\section{References}

[1] Virji S., Huang J., Kaner R. B., Weiller B. H.: Polyaniline nanofiber gas sensors: Examination of response mechanisms. Nano Letters, 4, 491-496 (2004). DOI: 10.1021/n1035122e

[2] Maiti S., Khatua B. B.: Polyaniline integrated carbon nanohorn: A superior electrode materials for advanced energy storage. Express Polymer Letters, 8, 895-907 (2014).

DOI: $10.3144 /$ expresspolymlett.2014.91

[3] Tian Z., Yu H., Wang L., Saleem M., Ren F., Ren P., Chen Y., Sun R., Sun Y., Huang L.: Recent progress in the preparation of polyaniline nanostructures and their applications in anticorrosive coatings. RSC Advances, 4, 28195-28208 (2014).

DOI: $10.1039 / \mathrm{C} 4 \mathrm{RA} 03146 \mathrm{~F}$

[4] Shahhosseini L., Nateghi M. R., SheikhSivandi S.: Electrochemical synthesis of polymer based on 4-(2-thienyl) benzenamine in aqueous solutions: Electrochemical properties, characterization and application. Synthetic Metals, 211, 66-74 (2016).

DOI: 10.1016/j.synthmet.2015.11.015

[5] Sudha J. D., Sivakala S., Chandrakanth C. K., Neethu K. S., Rohini K. N., Ramakrishnan R.: Percolated conductive polyaniline-clay nanocomposite in polyvinyl chloride through the combined approach porous template and self-assembly. Express Polymer Letters, 8, 107115 (2014).

DOI: $10.3144 /$ expresspolymlett.2014.13

[6] Luo Y., Wang X., Guo W., Rohwerder M.: Growth behavior of initial product layer formed on $\mathrm{Mg}$ alloy surface induced by polyaniline. Journal of the Electrochemical Society, 162, C294-C301 (2015).

DOI: $10.1149 / 2.1101506 j \mathrm{jes}$

[7] Sim B., Chae H. S., Choi H. J.: Fabrication of polyaniline coated iron oxide hybrid particles and their dual stimuli-response under electric and magnetic fields. Express Polymer Letters, 9, 736-743 (2015).

DOI: $10.3144 /$ expresspolymlett.2015.68

[8] Wang L. X., Soczka-Guth T., Havinga E., Müllen K.: Poly(phenylenesulfidephenylenamine) (PPSA) - The 'compound' of polyphenylenesulfide with polyaniline. Angewandte Chemie International Edition, 35, 14951497 (1996). DOI: 10.1002/anie.199614951

[9] Wei Y., Yang C., Wei G., Feng G.: A new synthesis of aniline oligomers with three to eight amine units. Synthetic Metals, 84, 289-291 (1997). DOI: $10.1016 / \mathrm{S} 0379-6779(97) 80756-4$

[10] Shao Z., Yu Z., Hu J., Chandrasekaran S., Lindsay D. M., Wei Z., Faul C. F. J.: Block-like electroactive oligo (aniline)s: Anisotropic structures with anisotropic function. Journal of Materials Chemistry, 22, 16230-16234 (2012).

DOI: $10.1039 / \mathrm{C} 2 J M 32278 \mathrm{~A}$ 
[11] Kim T-G., Park J-W.: Synthesis of poly(oligoaniline)s with structures controlled over three different oxidation states. Journal of Polymer Science Part A: Polymer Chemistry, 50, 1851-1860 (2012).

DOI: $10.1002 /$ pola. 25960

[12] Qu G., Li F., Berda E. B., Chi M., Liu X., Wang C., Chao D.: Electroactive polyurea bearing oligoaniline pendants: Electrochromic and anticorrosive properties. Polymer, 58, 60-66 (2015).

DOI: $10.1016 /$ j.polymer.2014.12.033

[13] Li F., Zhou M., Wang J., Liu X., Wang C., Chao D.: Synthesis and electrochemical properties of electroactive hyperbranched poly(aryl ether ketone) bearing oligoaniline segments. Synthetic Metals, 205, 42-47 (2015). DOI: 10.1016/j.synthmet.2015.03.019

[14] Wang S., Chao D., Berda E. B., Jia X., Yang R., Wang C.: Multicolor electrochromic performance of electroactive poly(amic acid) containing pendant oligoaniline, azobenzene and sulfonic acid groups. Electrochimica Acta, 89, 594-599 (2013).

DOI: $10.1016 /$ j.electacta.2012.10.149

[15] Huang L., Zhuang X., Hu J., Lang L., Zhang P., Wang Y., Chen X., Wei Y., Jing X.: Synthesis of biodegradable and electroactive multiblock polylactide and aniline pentamer copolymer for tissue engineering applications. Biomacromolecules, 9, 850-858 (2008).

DOI: $10.1021 / \mathrm{bm} 7011828$

[16] Gharibi R., Yeganeh H., Gholami H., Hassan Z. M.: Aniline tetramer embedded polyurethane/siloxane membranes and their corresponding nanosilver composites as intelligent wound dressing materials. RSC Advances, 4, 62046-62060 (2014). DOI: $10.1039 / C 4 R A 11454 J$

[17] Huang L., Hu J., Lang L., Wang X., Zhang P., Jing X., Wang X., Chen X., Lelkes P. I., MacDiarmid A. G., Wei Y.: Synthesis and characterization of electroactive and biodegradable ABA block copolymer of polylactide and aniline pentamer. Biomaterials, 28, 1741-1751 (2007). DOI: 10.1016/j.biomaterials.2006.12.007

[18] Hardy C. G., Islam M. S., Gonzalez-Delozier D., Morgan J. E., Cash B., Benicewicz B. C., Ploehn H. J., Tang C.: Converting an electrical insulator into a dielectric capacitor: End-capping polystyrene with oligoaniline. Chemistry of Materials, 25, 799-807 (2013).

DOI: $10.1021 / \mathrm{cm} 304057 \mathrm{f}$

[19] Huang T-C., Yeh T-C., Huang H-Y., Ji W-F., Chou YC., Hung W-I., Yeh J-M., Tsai M-H.: Electrochemical studies on aniline-pentamer-based electroactive polyimide coating: Corrosion protection and electrochromic properties. Electrochimica Acta, 56, 10151-10158 (2011).

DOI: $10.1016 /$ j.electacta.2011.08.114

[20] Huang T-C., Su Y-A., Yeh T-C., Huang H-Y., Wu C-P., Huang K-Y., Chou Y-C., Yeh J-M., Wei Y.: Advanced anticorrosive coatings prepared from electroactive epoxy- $\mathrm{SiO}_{2}$ hybrid nanocomposite materials. Electrochimica Acta, 56, 6142-6149 (2011).

DOI: $10.1016 /$ j.electacta.2011.04.053
[21] Huang H-Y., Lee Y-T., Yeh L-C., Jian J-W., Huang T-C., Liang H-T., Yeh J-M., Chou Y-C.: Photoactively electroactive polyamide with azo group in the main chain via oxidative coupling polymerization. Polymer Chemistry, 4, 343-350 (2013). DOI: $10.1039 / \mathrm{C} 2 \mathrm{PY} 20374 \mathrm{~J}$

[22] Huang T-C., Yeh T-C., Huang H-Y., Ji W-F., Lin T-C., Chen C-A., Yang T-I., Yeh J-M.: Electrochemical investigations of the anticorrosive and electrochromic properties of electroactive polyamide. Electrochimica Acta, 63, 185-191 (2012).

DOI: 10.1016/j.electacta.2011.12.087

[23] Yeh T-C., Huang T-C., Huang H-Y., Huang Y-P., Cai Y-T., Lin S-T., Wei Y., Yeh J-M.: Electrochemical investigations on anticorrosive and electrochromic properties of electroactive polyurea. Polymer Chemistry, 3, 2209-2216 (2012).

DOI: 10.1039/C2PY20061A

[24] Huang H-Y., Jian J-W., Lee Y-T., Li Y-T., Huang T-C., Chang J-H., Yeh L-C., Yeh J-M.: Effect of photoisomerization on the electroactivity and electrochromic behavior of aniline pentamer-based polymers with azo chromophore as reversibly switchable pendant group. Polymer, 53, 4967-4976 (2012).

DOI: $10.1016 /$ j.polymer.2012.09.003

[25] Wang S., Chao D., Berda E. B., Jia X., Yang R., Wang X., Jiang T., Wang C.: Fabrication of electroactive oligoaniline functionalized poly(amic acid) nanofibers for application as an ammonia sensor. RSC Advances, 3, 4059-4065 (2013).

DOI: 10.1039/C3RA00056G

[26] Wang S., Berda E. B., Lu X., Li X., Wang C., Chao D.: Tuning the fluorescent response of a novel electroactive polymer with multiple stimuli. Macromolecular Rapid Communications, 34, 1648-1653 (2013). DOI: $10.1002 /$ marc. 201300448

[27] Huang T-C., Lin S-T., Yeh L-C., Chen C-A., Huang HY., Nian Z-Y., Chen H-H., Yeh J-M.: Aniline pentamerbased electroactive polyimide prepared from oxidation coupling polymerization for electrochemical sensing application. Polymer, 53, 4373-4379 (2012).

DOI: $10.1016 /$ j.polymer.2012.07.064

[28] Iijima S.: Helical microtubules of graphitic carbon. Nature, 354, 56-58 (1991). DOI: $10.1038 / 354056 \mathrm{a} 0$

[29] Belin T., Epron F.: Characterization methods of carbon nanotubes: A review. Materials Science and Engineering: B, 119, 105-118 (2005). DOI: $10.1016 /$ j.mseb.2005.02.046

[30] Park S., Vosguerichian M., Bao Z.: A review of fabrication and applications of carbon nanotube film-based flexible electronics. Nanoscale, 5, 1727-1752 (2013). DOI: 10.1039/C3NR33560G 
[31] Pradhan A. K., Prusty G., Swain S. K.: Characterization of polyacrylonitrile nanocomposites by reinforcement of functionalized single-walled carbon nanotubes. Polymer-Plastics Technology and Engineering, 53, 784-789 (2014). DOI: $10.1080 / 03602559.2014 .886042$

[32] Prusty G., Das R., Swain S. K.: Influence of functionalized single-walled carbon nanotubes on morphology, conducting and oxygen barrier properties of poly(acrylonitrile-co-starch). Composites Part B: Engineering, 62, 236-241 (2014).

DOI: 10.1016/j.compositesb.2014.03.006

[33] Pradhan A. K., Swain S. K.: Oxygen barrier of multiwalled carbon nanotube/polymethyl methacrylate nanocomposites prepared by in situ method. Journal of Materials Science and Technology, 28, 391-395 (2012). DOI: 10.1016/S1005-0302(12)60073-5

[34] Chauhan N., Narang J., Pundir C. S.: Fabrication of multiwalled carbon nanotubes/polyaniline modified $\mathrm{Au}$ electrode for ascorbic acid determination. Analyst, 136, 1938-1945 (2011). DOI: $10.1039 / \mathrm{C} 0 \mathrm{AN} 00218 \mathrm{~F}$

[35] Zhang X., Lai G., Yu A., Zhang H.: A glassy carbon electrode modified with a polyaniline doped with silicotungstic acid and carbon nanotubes for the sensitive amperometric determination of ascorbic acid. Microchimica Acta, 180, 437-443 (2013). DOI: $10.1007 / \mathrm{s} 00604-013-0939-1$

[36] Padayatty S. J., Katz A., Wang Y., Eck P., Kwon O., Lee J-H., Chen S., Corpe C., Dutta A., Dutta S. K., Levine M.: Vitamin $\mathrm{C}$ as an antioxidant: Evaluation of its role in disease prevention. Journal of the American College of Nutrition, 22, 18-35 (2003).

DOI: $10.1080 / 07315724.2003 .10719272$

[37] Jeon I-Y., Tan L-S., Baek J-B.: Synthesis and electrical properties of polyaniline/polyaniline grafted multiwalled carbon nanotube mixture via in situ static interfacial polymerization. Journal of Polymer Science Part A: Polymer Chemistry, 48, 1962-1972 (2010). DOI: $10.1002 /$ pola. 23963

[38] Huang T-C., Yeh L-C., Huang H-Y., Nian Z-Y., Yeh YC., Chou Y-C., Yeh J-M., Tsai M-H.: The use of a carbon paste electrode mixed with multiwalled carbon nanotube/electroactive polyimide composites as an electrode for sensing ascorbic acid. Polymer Chemistry, 5, 630-637 (2014).

DOI: $10.1039 / \mathrm{C} 3 \mathrm{PY} 00787 \mathrm{~A}$

[39] Okpalugo T. I. T., Papakonstantinou P., Murphy H., McLaughlin J., Brown N. M. D.: High resolution XPS characterization of chemical functionalised MWCNTs and SWCNTs. Carbon, 43, 153-161 (2005).

DOI: $10.1016 /$ j.carbon.2004.08.033

[40] Yang S-Y., Lin W-N., Huang Y-L., Tien H-W., Wang JY., Ma C-C. M., Li S-M., Wang Y-S.: Synergetic effects of graphene platelets and carbon nanotubes on the mechanical and thermal properties of epoxy composites. Carbon, 49, 793-803 (2011).

DOI: $\underline{10.1016 / \text { j.carbon.2010.10.014 }}$
[41] He X., Zhang F., Wang R., Liu W.: Preparation of a carbon nanotube/carbon fiber multi-scale reinforcement by grafting multi-walled carbon nanotubes onto the fibers. Carbon, 45, 2559-2563 (2007).

DOI: $10.1016 /$ j.carbon.2007.08.018

[42] Swain S. K., Pradhan A. K., Sahu H. S.: Synthesis of gas barrier starch by dispersion of functionalized multiwalled carbon nanotubes. Carbohydrate Polymers, 94, 663-668 (2013).

DOI: $10.1016 /$ j.carbpol.2013.01.056

[43] Zhang H., Li H. X., Cheng H. M.: Water-soluble multiwalled carbon nanotubes functionalized with sulfonated polyaniline. The Journal of Physical Chemistry B, 110, 9095-9099 (2006).

DOI: 10.1021/jp060193y

[44] Sun Y., Wilson S. R., Schuster D. I.: High dissolution and strong light emission of carbon nanotubes in aromatic amine solvents. Journal of the American Chemical Society, 123, 5348-5349 (2001).

DOI: $10.1021 / \mathrm{ja0041730}$

[45] Dhand C., Arya S. K., Singh S. P., Singh B. P., Datta M., Malhotra B. D.: Preparation of polyaniline/multiwalled carbon nanotube composite by novel electrophoretic route. Carbon, 46, 1727-1735 (2008). DOI: $10.1016 /$ j.carbon.2008.07.028

[46] Zhao H., Yuan W. Z., Tang L., Sun J. Z., Xu H., Qin A., Mao Y., Jin J. K., Tang B. Z.: Hybrids of triphenylamine-functionalized polyacetylenes and multiwalled carbon nanotubes: High solubility, strong donor-acceptor interaction, and excellent photoconductivity. Macromolecules, 41, 8566-8574 (2008).

DOI: $10.1021 / \mathrm{ma} 8014323$

[47] Zhai D., Liu B., Shi Y., Pan L., Wang Y., Li W., Zhang R., Yu G.: Highly sensitive glucose sensor based on Pt nanoparticle/polyaniline hydrogel heterostructures. ACS Nano, 7, 3540-3546 (2013).

DOI: $10.1021 / \mathrm{nn} 400482 \mathrm{~d}$

[48] Ambrosi A., Morrin A., Smyth M. R., Killard A. J.: The application of conducting polymer nanoparticle electrodes to the sensing of ascorbic acid. Analytica Chimica Acta, 609, 37-43 (2008).

DOI: 10.1016/j.aca.2007.12.017

[49] Chen S., Xu L., Yang Y., Li B., Hou J.: Improved electrocatalytic behavior of ascorbic acid by crosslinked polyaniline with enhanced conductivity. Analytical Methods, 3, 2374-2378 (2011).

DOI: $10.1039 / \mathrm{C} 1 \mathrm{AY} 05310 \mathrm{H}$

[50] O’Connell P. J., Gormally C., Pravda M., Guilbault G. G.: Development of an amperometric L-ascorbic acid (Vitamin C) sensor based on electropolymerised aniline for pharmaceutical and food analysis. Analytica Chimica Acta, 431, 239-247 (2001).

DOI: $10.1016 / \mathrm{S} 0003-2670(00) 01330-1$

[51] Zhang L.: Electrochemical synthesis of self-doped polyaniline and its use to the electrooxidation of ascorbic acid. Journal of Solid State Electrochemistry, 11, 365-371 (2007). DOI: $10.1007 / \mathrm{s} 10008-006-0151-\mathrm{x}$ 
[52] Yeh L-C., Huang T-C., Huang Y-P., Huang H-Y., Chen H-H., Yang T-I., Yeh J. M.: Synthesis electroactive polyurea with aniline-pentamer-based in the main chain and its application in electrochemical sensor. Electrochimica Acta, 94, 300-306 (2013).

DOI: 10.1016/j.electacta.2013.01.073

[53] Roy A. K., Nisha V. S., Dhand C., Malhotra B. D.: Molecularly imprinted polyaniline film for ascorbic acid detection. Journal of Molecular Recognition, 24, 700-706 (2011).

DOI: $\underline{10.1002 / \mathrm{jmr} .1104}$
[54] Ragupathy D., Park J. J., Lee S. C., Kim J. C., Gomathi P., Kim M. K., Lee S. M., Ghim H. D., Rajendran A., Lee S. H., Jeon K. M.: Electrochemical grafting of poly(2,5-dimethoxy aniline) onto multiwalled carbon nanotubes nanocomposite modified electrode and electrocatalytic oxidation of ascorbic acid. Macromolecular Research, 19, 764-769 (2011).

DOI: $10.1007 / \mathrm{s} 13233-011-0802-3$

[55] Abdelwahab A. A., Kim D-M., Halappa N. M., Shim Y-B.: A selective catalytic oxidation of ascorbic acid at the aminopyrimidyl functionalized-conductive polymer electrode. Electroanalysis, 25, 1178-1184 (2013). DOI: $\underline{10.1002 / \text { elan.201200650 }}$ 